\title{
Robotic-Assisted and Image-Guided MRI-Compatible Stereoelectroencephalography
}

\author{
Jeffery A. Hall, Hui Ming Khoo
}

\begin{abstract}
Background: Stereoelectroencephalography has been in regular use at the Montreal Neurological Institute since 1972. The technique has been in constant evolution to incorporate advances in materials, imaging, and robotics technology. MRI-compatible electrodes were introduced in 2007 and robotics in 2011. Here we report on the technique, safety, and advantages of our current method of stereoelectroencephalography implantation. Methods: We retrospectively reviewed all patients who underwent stereoelectroencephalography by the senior author. Technical, clinical, and radiological complications, and postimplantation outcomes were analyzed. Only patients implanted with MRI-compatible electrodes were included to review MRI abnormalities with electrodes in situ. Results: A total of 53 patients were implanted with 550 electrodes (average $=10.4$ per patient), for an average duration of 14.6 days. There was no mortality, infection, or new neurologic deficit. Two patients had a superficial screw plunge without clinical consequence. Four patients demonstrated asymptomatic MRI abnormalities ( $7.54 \%$ per patient, or $0.72 \%$ per electrode). MRI with electrodes in situ was used for neuronavigation in all 29 who underwent resection and yielded a histopathological diagnosis of focal cortical dysplasia in 15 MRI-negative patients. Conclusions: The technique of stereoelectroencephalography described here was associated with no clinical morbidity although not without technical complications or radiologic (MRI) abnormalities. We should therefore remain vigilant in refining the technique and minimizing the number of electrodes required to answer a well-developed hypothesis regarding the epileptogenic zone. The use of MRI-compatible electrodes allowed neuronavigation using the images with the electrodes in situ, which was useful to tailor the eventual definitive resection and in localizing MRI-negative lesions.
\end{abstract}

RÉSUMÉ: La stéréo-électroencéphalographie assistée par robot et guidée par l'image peut être compatible avec la technique d'IRM. Contexte: C'est depuis 1972 que l'Institut neurologique de Montréal utilise couramment la stéréo-électroencéphalographie (SEEG). Cette technique n'a cessé d'évoluer en intégrant les avancées effectuées dans la technologie des matériaux, de l'imagerie et de la robotique. À cet égard, précisons que des électrodes compatibles avec l'IRM, de même que l'usage de la robotique, ont été respectivement introduits en 2007 et en 2011 . Nous voulons ici faire état des aspects techniques et sécuritaires, mais aussi des avantages, liés à la mise en place de notre méthode actuelle de SEEG. Méthodes: Nous avons examiné de façon rétrospective tous les patients à qui l'auteur principal avait demandé de passer une SEEG. Tant les complications techniques, cliniques et radiologiques que les impacts consécutifs à la mise en place de cette méthode ont été analysés. Seuls les patients à qui l'on avait implanté des électrodes compatibles avec l'IRM ont été inclus dans notre étude afin que nous puissions nous pencher sur les anomalies techniques propres à cette méthode. Résultats: On a implanté chez 53 patients un total de 550 électrodes (moyenne $=10,4$ par patient), et ce, pour une durée moyenne de 14,6 jours. Aucun cas de mortalité, d'infection ou de déficit neurologique n'est survenu. Fait à noter, deux patients ont vu leur vis s'enfoncer sans que cela n'entraîne des conséquences cliniques. De plus, on a détecté chez quatre patients des anomalies techniques asymptomatiques (7,54\% par patient ou 0,72\% par électrode). Enfin, la technique d'IRM couplée in situ à des électrodes a été utilisée dans un contexte de neuro-navigation chez tous les 29 patients qui avaient subi une résection. En outre, grâce à cette technique, on a pu obtenir chez 15 patients dont le cerveau était d'apparence normale un diagnostic histopathologique de dysplasie corticale focale. Conclusions: La technique de SEEG décrite ici n'a pas été associée à une forme ou une autre de morbidité clinique. Cela dit, des complications techniques et des anomalies liées à l'IRM se sont produites. Améliorer cette technique exige donc de rester vigilants et aussi de diminuer le nombre d'électrodes nécessaires afin d'étayer l'hypothèse, déjà bien admise, concernant les foyers épileptogènes. L'utilisation d'électrodes compatibles avec la technique d'IRM nous a aussi permis d'effectuer un examen de neuro-navigation en utilisant in situ des images. Cela s'est avéré utile car on a pu ainsi adapter d'éventuelles résections finales et localiser par IRM des lésions négatives.

Keywords: Robotics, Stereoelectroencephalography, Depth electrode, Image-guided

doi:10.1017/cjn.2017.240

Can J Neurol Sci. 2018; 45: 35-43

\section{INTRODUCTION}

Image-guided placement of intracranial surface and depth electrodes for the characterization of epileptic foci was first promoted 52 years ago ${ }^{1}$ and is currently a crucial step in the presurgical evaluation of many patients with pharmacoresistant epilepsy. Stereoelectroencephalography (SEEG) was developed in

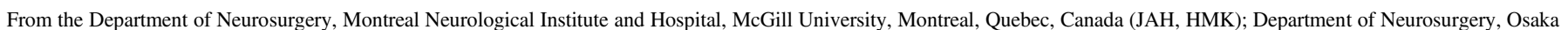
University Graduate School of Medicine, Suita, Japan (HMK).

Received April 3, 2017. Final Revisions Submitted June 20, 2017. Date of Acceptance July 6, 2017.

Correspondence to: Jeffery A. Hall, Department of Neurology and Neurosurgery, Montreal Neurological Institute and Hospital, McGill University, $122 \mathrm{C}-3801$ University Avenue, Montreal, Quebec, H3A 3B4, Canada. Email: jeffery.hall@mcgill.ca 
Paris using a frame-based method that made use of intraoperative angiography to avoid vascular complications. ${ }^{2}$ The aim of SEEG is to determine the epileptogenic zone- that is, the region of ictal onset and immediate spread-in three dimensions. It was first implemented at the Montreal Neurological Institute in $1972^{3}$ and has been associated with a very low rate of morbidity. ${ }^{4,5}$ The procedure has been in constant evolution to take advantage of advances in materials and innovation in imaging and robotics technology. We began using magnetic resonance imaging (MRI)-compatible electrodes (DIXI Microtechniques, Besancon, France) in 2007 and a Robotic Surgical Assistant (ROSA, Medtech, Montpellier, France) in 2011. Previous studies have shown a greater degree of accuracy with the robot-assisted technique. ${ }^{6,7}$ SEEG electrodes from historical cases were not MRI-compatible, and thus a thorough review of MRI findings was not possible. In our study, for the first time, we showed MRI findings in a relatively large cohort of patients with pharmacoresistant epilepsy who had MRI with electrodes in situ following implantation of SEEG electrodes. We describe the current technique of SEEG implantation at our center and aim to assess its safety and advantages.

\section{Methods}

We performed a retrospective chart review of all patients with MRI-compatible intracranial SEEG electrodes implanted by the senior author $(\mathrm{JH})$. The research ethics board of the Montreal Neurological Institute and Hospital approved the review (no. NEU-14-101). All patients had preoperative enhanced MRI for image guidance during implantation of SEEG electrodes as well as postimplantation MRI with the electrodes in situ.

Initially, electrodes were inserted using a frameless technique with a double-chuck articulated $\operatorname{arm}^{8}$ and the StealthStation neuronavigation system (Medtronic, Minneapolis, MN, United States) with image guidance by global acquisition gadolinium-enhanced MRI. Avascular trajectories were chosen from the scalp entry point to the intracranial target. Once the plane was obtained, a percutaneous craniostomy was performed with a $1.3-\mathrm{mm}$ drill bit. A hollow anchoring screw measuring $2.5 \mathrm{~cm}$ in length was then secured in place with an adapted screwdriver (DIXI). The neuronavigation system was used to calculate the distance from the tip of the anchoring screw to the target. This distance was then translated to a measuring tool (DIXI), and a stylet (DIXI) was passed through the hollow screw to make a path for the electrode. Coagulation was sometimes required if the dura had not been breached by the anchoring screw. When the stylet was removed, the electrode was inserted to the proper depth and secured to the anchoring screw. The electrodes measure $0.8 \mathrm{~mm}$ in diameter.

Since 2011, we used ROSA for stereotaxy and the StealthStation neuronavigation system for verification and for depth measurement in all cases. Avascular trajectories are planned on the ROSA software with image guidance using global acquisition gadolinium-enhanced MRI coregistered onto global acquisition thin-cut computed tomography (CT) angiography (slice thickness $=1 \mathrm{~mm}$ ). The stereotaxic craniostomy, anchoring screw, and electrode placement are identical to that described above.

The anchoring screws are made of titanium and the electrodes are made of platinum and iridium (DIXI Microtechniques, Besancon, France). Preimplantation CT angiography for stereotaxy planning was acquired using a Toshiba CT machine (Aquilion ONE, Toshiba, Tokyo, Japan). Both preimplantation MRI for stereotaxy planning and postimplantation MRI (T1- and T2-weighted images) with electrode in situ was acquired using a 1.5-Tesla magnetic field machine (Signa [GE Medical Systems, Chicago, IL, United States] prior to November of 2014 and Ingenia [Philips Medical Systems, Amsterdam, The Netherlands] thereafter). A T1-weighted image was acquired using the following sequences: prior to November of 2014: slice thickness $1.0 \mathrm{~mm}$, repetition time (TR) $23 \mathrm{~ms}$, echo time (TE) $8 \mathrm{~ms}$, flip angle 20 or 65 degrees; from November of 2014: slice thickness $0.78 \mathrm{~mm}$, TR $7.9 \mathrm{~ms}$, TE $3.5 \mathrm{~ms}$, flip angle 6 degrees). A T2-weighted image was acquired using the following sequences: prior to November 2014: slice thickness 1.2 to $1.6 \mathrm{~mm}$, TR 3.6 to $4.1 \mathrm{~ms}$, TE $1.2 \mathrm{~ms}$, flip angle 20 or 65 degrees; from November 2014: slice thickness $2 \mathrm{~mm}$; TR $2800 \mathrm{~ms}$, TE $475 \mathrm{~ms}$; flip angle 90 degrees).

Postimplantation MRI images with electrodes in situ were employed for evaluation of complications and to reconstruct global images for later use in neuronavigation protocols during resection of the epileptic focus. While there is some metallic artifact, the electrodes and electrode contacts are best visualized on T2-weighted images. T1-weighted images were employed as reference in our neuronavigation protocols, and the T2-weighted images were coregistered.

A total of 55 consecutive patients were identified from September of 2007 to June of 2017. Two patients were excluded from analysis: one because not all of the implanted electrodes were MRI-compatible and postimplantation MRI was not acquired, and the other because it was not performed for SEEG (but for thermoablation). This was done to provide a homogenous cohort of patients undergoing SEEG for pharmacoresistant epilepsy, all of whom had MRI with the electrodes in situ. The MRI images with electrodes in situ were used for image guidance at the time of definitive resection in all patients.

The factors studied included technique of implantation (manual vs. robotic-assisted), radiological morbidity, clinical morbidity, and mortality. We also calculated the MRI-positive rate of patients diagnosed with focal cortical dysplasia (FCD) on histopathology. The MRI findings were extracted from the neuroradiology report of our center based on 1.5-Tesla MRI.

\section{RESULTS}

The details pertaining to semiology, MR findings, FDG-PET, and neuropsychology findings of the patients are summarized in Table 1. Both of the techniques described here allowed successful implantation in all cases. Between September of 2007 and March of 2011, 20 patients $(11$ males; mean age $=34.6 \pm 9.8$ years, range $=18-53$ ) were implanted using the manual technique with a total of 184 electrodes (Table 1, patients 1-20). Between July of 2011 and June of 2017, 33 patients $(23$ males; mean age $=30.1 \pm 9.4$ years, range $=$ 14-53) were implanted using the robot-assisted technique with a total of 366 electrodes (Table 1, patients 21-53). Therefore, among the 53 patients included in our analysis, 550 electrodes were implanted, for an average of 10.4 per patient. The duration of implantation ranged from 7 to 31 days, with an average of 14.6 days.

Placement of the anchoring screw requires gentle forward pressure with the screwdriver to secure it to the bone. On two occasions, both associated with the electrodes placed through the temporal bone for hippocampal targets, the screw penetrated the cortex. In these two cases, a 1-cm incision and enlargement of the craniostomy was required to retrieve the screw found at the level of the inner table. While this technical complication resulted in no clinical 
Table 1: Summary of semiology, imaging, neuropsychology data, and preimplantation hypothesis $(N=53)$

\begin{tabular}{|c|c|c|c|c|c|c|}
\hline $\mathbf{P t}$ & $\begin{array}{c}\text { Age/ } \\
\text { gender }\end{array}$ & Seizure semiology & MRI findings & FDG-PET & Neuropsychological data & $\begin{array}{c}\text { Pre- } \\
\text { implantation } \\
\text { hypothesis }\end{array}$ \\
\hline 1 & $44 / \mathrm{M}$ & $\begin{array}{l}\text { No aura. Arrest of activity, unresponsive, oral and manual automatisms. Post-ictal confusion, } \\
\text { fatigue and L side headache }\end{array}$ & $\begin{array}{l}\text { L T intraventricle cyst with discret } \\
\text { wm gliosis. Bil shape } \mathrm{Hc} \\
\text { abnormalities }\end{array}$ & Not performed & Bil $\mathrm{T}$ dysfunction $\mathrm{L}>\mathrm{R}$ & Bil TLE \\
\hline 2 & $47 / \mathrm{F}$ & $\begin{array}{l}\text { Aura: epigastric and numb sensation in } L \text { forearm. Stares, laughs, oral and gestural } \\
\text { automatisms. SGTC with apnea and cyanosis. Prolonged postictal confusion }\end{array}$ & Normal & Not performed & Bil $\mathrm{T}$ dysfunction & R TLE \\
\hline 3 & $32 / \mathrm{F}$ & $\begin{array}{l}\text { Aura: rising epigastric sensation, déjà vu or premonition } \\
\text { 1. Arrest of activity, chewing, moaning, some restlessness } \\
\text { 2. Stares, terror, high pitch moan, bi-manual automatisms, R arm dystonia. Post-ictal } \\
\text { amnesia. }\end{array}$ & Normal & Not performed & Bil T dysfunction & FTLE \\
\hline 4 & $27 / \mathrm{F}$ & $\begin{array}{l}\text { Aura: headache L OF (root of the nose), sometimes epigastric with palpitations. Stares, } \\
\text { immobile and mute, amnesia. Occ SGTC }\end{array}$ & $\begin{array}{l}\text { L sphenoid fibrous dysplasia, and } \\
\text { OF encephalocele (post-op) }\end{array}$ & Not performed & Mild dysfunction $\mathrm{L}$ mesial $\mathrm{T}$ & L FLE \\
\hline 5 & $31 / \mathrm{M}$ & $\begin{array}{l}\text { No aura. Nocturnal. Arousal, motor agitation, horizontal body mvts, with or without head } \\
\text { deviation, occ. posturing of } \mathrm{L}>\mathrm{R} \text { arm and chewing }\end{array}$ & L inf. P FCD & Not performed & L FT dysfunction & L PQE \\
\hline 6 & $53 / \mathrm{F}$ & $\begin{array}{l}\text { 1. Aura: Rising chest sensation, fear } \\
\text { 2. No aura. Loss of awareness, vocalization, L face and arms jerking, agitation. Post-ictal } \\
\text { fatigue and speech impaired }\end{array}$ & $\begin{array}{l}\text { R Am and Hc atrophy and L OF } \\
\text { FCD }\end{array}$ & Not performed & $\mathrm{L}$ mesial $\mathrm{T}$ dysfunction & L FLE \\
\hline 7 & $16 / \mathrm{M}$ & No aura. Asymmetric tonic posture with head turning to $\mathrm{L}$ & Normal & $\begin{array}{l}\text { Diffuse } \\
\text { hypometabolism }\end{array}$ & Diffuse dysfunction & L FLE \\
\hline 8 & $28 / \mathrm{M}$ & $\begin{array}{l}\text { Aura: déjà vu, dizziness and hot flashes. Hesitant, oral automatisms, sometimes speech } \\
\text { disturbance but alert }\end{array}$ & Mild diffuse brain atrophy & $\begin{array}{l}\text { bil T } \\
\text { hypometabolism }\end{array}$ & Bil mesial $\mathrm{T}$ dysfunction & Bi TLE \\
\hline 9 & $42 / \mathrm{M}$ & $\begin{array}{l}\text { No aura. Nocturnal. Hypermotor seizures with agitation, complex gestural automatisms, tonic } \\
\text { phase (head and eyes to L). Rapid recuperation but amnesia, fatigue and stuttering }\end{array}$ & Normal & R FT abnormalities & $\begin{array}{l}\text { Widespread dysfunction, } \\
\text { possibly more on } \mathrm{R}\end{array}$ & R FLE \\
\hline 10 & $25 / \mathrm{F}$ & No aura. Nocturnal, vocalization, clonic contractions of face, dystonic posturing & Normal & $\begin{array}{l}\text { R post } \mathrm{F} \\
\text { hypometabolism }\end{array}$ & Normal profile & R FLE \\
\hline 11 & $43 / \mathrm{F}$ & $\begin{array}{l}\text { No aura. Nocturnal. Frequent SGTC. Stares, oral automatisms, R arm flexion and stiffening, } \\
\text { blinking, facial flushing. Post-ictal amnesia, confused and fatigue }\end{array}$ & L Hc atrophy and signal change & $\begin{array}{l}\text { bil T } \\
\text { hypometabolism }\end{array}$ & Bil mesial $\mathrm{T}$ dysfunction & Bil TLE \\
\hline 12 & $33 / \mathrm{M}$ & $\begin{array}{l}\text { No aura (occ. olfactory aura and déjà vu). Stares, automatisms and frequent SGTC. Post-ictal } \\
\text { amnesia }\end{array}$ & Hydrocephalus & not performed & $\begin{array}{l}\text { Non-dominant mesial } \mathrm{T} \\
\text { dysfunction }\end{array}$ & $\begin{array}{l}\text { L mTLE vs } \\
\text { bi TLE }\end{array}$ \\
\hline 13 & $40 / \mathrm{M}$ & $\begin{array}{l}\text { No aura. Confused, stares, unresponsive, oral and manual automatisms. Ictal and post-ictal } \\
\text { coughing. Post-ictal amnesia and confusion }\end{array}$ & L MTS & not performed & Bil T dysfunction & Bil TLE \\
\hline 14 & $21 / \mathrm{M}$ & $\begin{array}{l}\text { Aura: bad taste, nausea and epigastric sensation. Chewing, swallowing, moaning, L hand } \\
\text { dystonia, confusion. Occ blurry vision. Occ SGTC }\end{array}$ & $\begin{array}{l}\text { R MTS, L O uligyria/ } \\
\text { encephalomalacia, L P gliosis/ } \\
\text { dysplasia }\end{array}$ & not performed & $\begin{array}{l}\text { Diffuse interference with bil T } \\
\text { dysfunction }\end{array}$ & R TLE \\
\hline 15 & $48 / \mathrm{M}$ & $\begin{array}{l}\text { 1. Brief absence-like episodes with grimacing. Drooling and postictal amnesia. } \\
\text { 2. Confusion, head version to } R, R \text { hemibody tonic convulsion }\end{array}$ & Normal & not performed & $\mathrm{L} T$ dysfunction & L FLE \\
\hline 16 & $22 / \mathrm{F}$ & $\begin{array}{l}\text { Aura: numb feeling, foggy vision. Gestural automatisms, rubs frontal area and scalp with } \\
\text { R hand or both, eyes and head to L, L arm elevation and SGTC }\end{array}$ & Normal & not performed & $\begin{array}{l}\text { Diffuse interference (FT max), } \\
\text { not lateralizing }\end{array}$ & R FLE \\
\hline 17 & $33 / \mathrm{M}$ & $\begin{array}{l}\text { No aura. Asymmetrical tonic posture, } L \text { arm stiffening and elevation with or without } L \text { facial } \\
\text { pulling, head and body turn to R. Occ SGTC }\end{array}$ & $\mathrm{R}$ hemimegalencephaly & not performed & Diffuse interference & R FLE \\
\hline 18 & $38 / \mathrm{M}$ & $\begin{array}{l}\text { No aura. Nocturnal, arousal, grimace, facial flushing, contraction of facial muscles, smiling } \\
\text { and giggling, shakes head }\end{array}$ & Normal & $\begin{array}{l}\text { R FT } \\
\text { hypometabolism }\end{array}$ & Non-dominant disturbance FC & R FLE vs TLE \\
\hline 19 & $26 / \mathrm{F}$ & Olfactory aura, déjà vu, anxiety, staring, anxiousness, oral automatism & R Hc atrophy & $\begin{array}{l}\text { R FT mild } \\
\text { hypometabolism }\end{array}$ & Bil mesial $\mathrm{T}$ dysfunction & R TLE \\
\hline
\end{tabular}


Table 1. Continued

\begin{tabular}{|c|c|c|c|c|c|c|}
\hline $\mathbf{P t}$ & $\begin{array}{c}\text { Age/ } \\
\text { gender }\end{array}$ & Seizure semiology & MRI findings & FDG-PET & Neuropsychological data & $\begin{array}{l}\text { Pre- } \\
\text { implantation } \\
\text { hypothesis }\end{array}$ \\
\hline 20 & $39 / \mathrm{F}$ & $\begin{array}{l}\text { Olfactory aura with déjà vu. Arms and hands automatisms, oral automatisms. Post-ictal speech } \\
\text { deficit and often } L \text { frontal headache }\end{array}$ & L OF encephalocele & $\begin{array}{l}\mathrm{L} \mathrm{T} \text { anterior and } \\
\text { mesial } \\
\text { hypometabolism }\end{array}$ & L FT dysfunction & L FLE vs TLE \\
\hline 21 & $23 / \mathrm{F}$ & $\begin{array}{l}\text { Feeling of a presence, sensation over dorsolumbar spine. Tonic symmetrical posture with both } \\
\text { arms flexed, fingers automatisms, grimaces, apnea, rubefaction. Cluster of spasms }\end{array}$ & Normal & $\begin{array}{l}\text { Not clearly } \\
\text { lateralizing or } \\
\text { localizing }\end{array}$ & $? ? ?$ & FLE \\
\hline 22 & $36 / \mathrm{M}$ & $\begin{array}{l}\text { Aura: tachychardia, ascending or descending body sensation, echoing, dizziness. Agitation, } \\
\text { rotatory and horizontal mvts of body, grimaces, R UE dystonia, speech arrest. Rare SGTC }\end{array}$ & Normal & $\begin{array}{l}\text { L FT } \\
\text { hypometabolism }\end{array}$ & $\begin{array}{l}\text { Bil F L }>\text { R (parasagittal), and } \mathrm{R} \\
\text { T dysfunction }\end{array}$ & FLE \\
\hline 23 & $25 / \mathrm{M}$ & $\begin{array}{l}\text { Aura: feeling sick, fear, complex visual hallucinations. Head deviation to R, loss of awareness, } \\
\text { oral and } \mathrm{R} \text { arm automatisms. Post-ictal fatigue and } \mathrm{R} \text { side headache }\end{array}$ & Normal & $\begin{array}{l}\mathrm{R} \mathrm{T} \\
\text { hypometabolism }\end{array}$ & $\begin{array}{l}\text { Normal T function, atypical } \\
\text { speech }\end{array}$ & R TLE \\
\hline 24 & $25 / M$ & $\begin{array}{l}\text { No aura. Asymmetrical tonic posture, head deviation to L, agitation. Rapid recuperation, } \\
\text { discrete R side weakness }\end{array}$ & Normal & Not localizing & L FC dysfunction & L FLE \\
\hline 25 & $41 / \mathrm{M}$ & $\begin{array}{l}\text { Auras: rising epigastric sensation, bladder fullness. Arousal, stares, asymmetric tonic posture, } \\
\text { apnea. Rapid recuperation, post-ictal exhaustion, hyperventilation, no deficit }\end{array}$ & Normal & $\begin{array}{l}\text { Not clearly } \\
\text { lateralizing or } \\
\text { localizing }\end{array}$ & $\begin{array}{l}\text { Not clearly lateralizing or } \\
\text { localizing }\end{array}$ & FLE \\
\hline 26 & $36 / \mathrm{M}$ & $\begin{array}{l}\text { Nocturnal. No clear aura. Arousal, stares, tonic posture, pout, blinks. Rapid recuperation. } \\
\text { Goes back to sleep. Fatigue next morning }\end{array}$ & Normal & $\begin{array}{l}\mathrm{R} \mathrm{T} \text { mild } \\
\text { questionable } \\
\text { hypometabolism }\end{array}$ & Bil F dysfunction & FLE \\
\hline 27 & $36 / \mathrm{M}$ & $\begin{array}{l}\text { Mostly nocturnal attacks. Aura: cephalic sensation, palpitation, embarrassed feeling. } \\
\text { Hypermotor seizure, screams and intense agitation, fear. Post-ictal amnesia }\end{array}$ & Normal & $\begin{array}{l}\text { L F } \\
\text { hypometabolism }\end{array}$ & FC, not lateralized & FLE \\
\hline 28 & $45 / \mathrm{M}$ & $\begin{array}{l}\text { Aura: epigastric, pressure or pain or discomfort. Loss of awareness, restless, unresponsive and } \\
\text { mute. Occ SGTC. Post-ictal confusion and amnesia }\end{array}$ & $\begin{array}{l}\mathrm{RF} \text { encephalomacia and bil } \mathrm{Hc} \\
\text { atrophy }\end{array}$ & not performed & Diffuse interference & Bil TLE \\
\hline 29 & $31 / \mathrm{F}$ & $\begin{array}{l}\text { 1. Unresponsive, eyes wide opened, pupils dilated, immobile, no automatic behavior, occ fall } \\
\text { 2. L arm sensory aura, sometimes loss of awareness } \\
\text { 3. R arm sensory aura, speech impairment, loss of awareness }\end{array}$ & Bil Hc atrophy with increase signal & $\begin{array}{l}\text { R hemisphere } \\
\text { diffuse } \\
\text { hypometabolism }\end{array}$ & Diffuse interference & R PQE \\
\hline 30 & $21 / \mathrm{F}$ & $\begin{array}{l}\text { Vestibular aura: impression of movement or unsteadiness. L UE increased tone, loss of } \\
\text { awareness, L arm clonus, occ SGTC }\end{array}$ & Normal & not performed & bil post Q. dysfunction & R PQE \\
\hline 31 & $29 / \mathrm{F}$ & $\begin{array}{l}\text { Aura: unwell, hot sensation in the chest, rising epigastric sensation; changes of luminosity and } \\
\text { "flashes"; sometimes hyperacusis. Staring, oral automatisms, and occ. head version to L } \\
\text { and SGTC }\end{array}$ & Normal & $\begin{array}{l}\mathrm{R} \text { anterior } \mathrm{T} \\
\text { hypometabolism }\end{array}$ & R FT dysfunction & R FLE \\
\hline 32 & $53 / \mathrm{M}$ & $\begin{array}{l}\text { Aura: tingling sensation, cephalic, sometimes smiling and giggling. Arrest of activity, } \\
\text { hesitant, speech arrest. Occ head version to R, R hemibody clonic mvts, and SGTC }\end{array}$ & Hypothalamic hamartoma & not performed & L FT dysfunction & $\begin{array}{r}\text { hypothalamic } \\
\text { hamartoma }\end{array}$ \\
\hline 33 & $47 / \mathrm{M}$ & $\begin{array}{l}\text { No aura. Arrest of activity, staring, oral automatisms, elation, mute or laughing. Post-ictal } \\
\text { dysphasia, confusion, amnesia, frequent L F and peri-orbital headache. Occ SGTC }\end{array}$ & Normal & not performed & $\mathrm{F}>\mathrm{T}$ dysfunction & FLE vs TLE \\
\hline 34 & $37 / \mathrm{M}$ & Aura: auditory, deja-vu, speech and activity arrest, staring, loss of awareness & L Hc atrophy & $\begin{array}{l}\text { Bil T } \\
\text { hypometabolism }\end{array}$ & bil $\mathrm{T}$ dysfunction & Bil TLE \\
\hline 35 & $36 / \mathrm{M}$ & Verbal vocalization and hand rubbing & Bil multiple NH & $\begin{array}{l}\text { Not clearly } \\
\text { lateralizing or } \\
\text { localizing. }\end{array}$ & Bil FT dysfunction, $\mathrm{L}>\mathrm{R}$ & L TLE \\
\hline 36 & $33 / \mathrm{F}$ & $\begin{array}{l}\text { Aura: déjà vu. Loss of awareness, arrest of activity, staring and mute, chewing, blinking, } \\
\text { bi-manual automatisms, smiles or grimaces. Occ SGTC. Post-ictal amnesia, confusion }\end{array}$ & Normal & $\begin{array}{l}\mathrm{L} \text { anterior and } \\
\text { mesial T } \\
\text { hypometabolism }\end{array}$ & R T dysfunction & L PQE \\
\hline
\end{tabular}




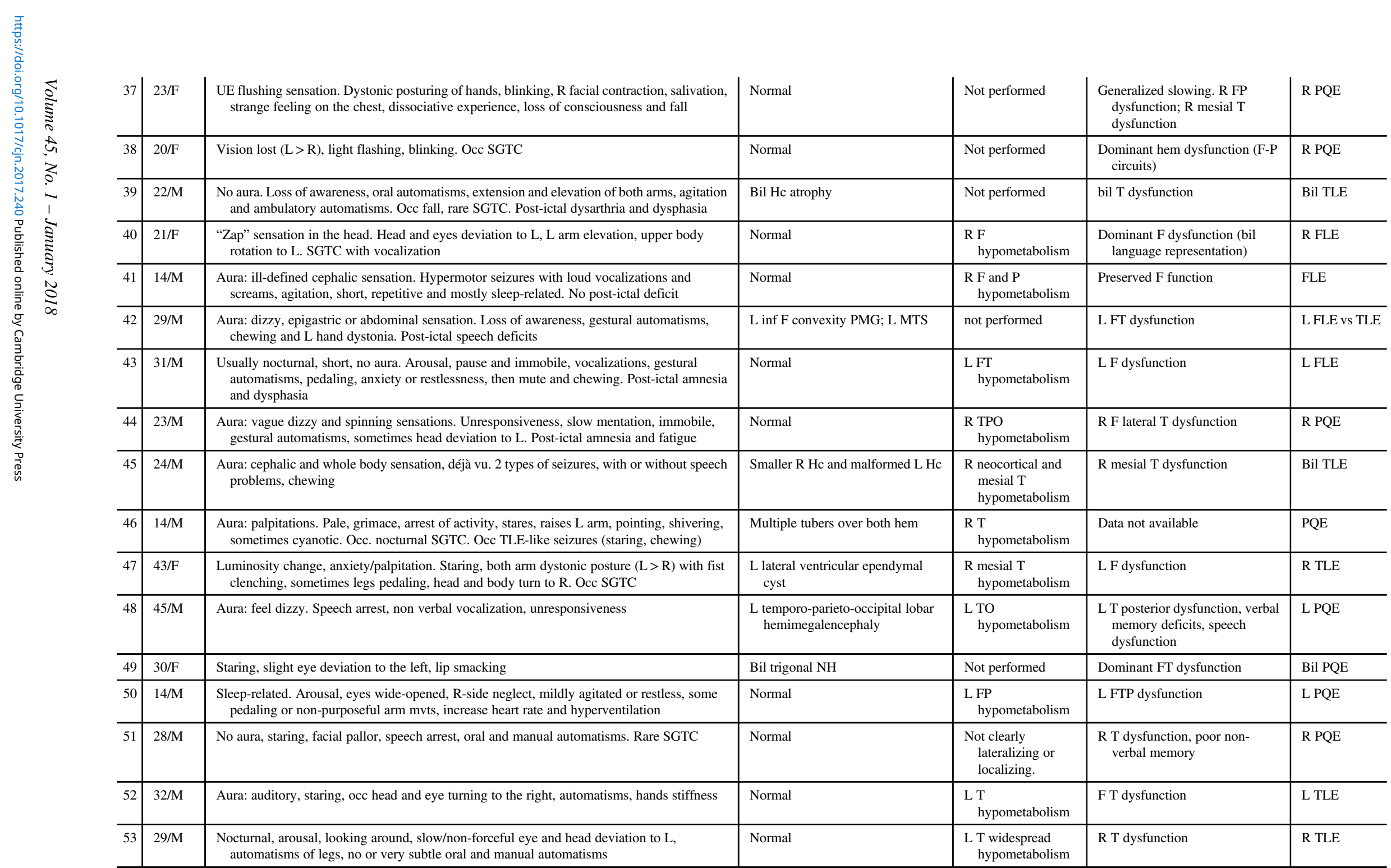

Ant: anterior; Bil: bilateral; C: central; F: female (in the column of gender), or frontal; FC: frontal-central; FCD: focal cortical dysplasia; FLE: frontal lobe epilepsy; Hem: hemisphere;

Hc: hippocampus; inf: inferior; L: left; M: male; max: maximum; MTS: mesial temporal sclerosis; mvts: movements; NH: nodular heterotopia; NL: non-lesional; O: occipital; occ: occasional;

OF: orbitofrontal; P: parietal; PMG: polymicrogyria; post: posterior; PQ: posterior quadrant; PQE: posterior quadrant epilepsy; Pt: patient; R: right; SGTC: secondary generalized tonic clonic seizure; T: temporal; TLE: temporal lobe epilepsy; UE: upper extremity. 
consequences, its description is mentioned here due to highlight the need for very gentle pressure upon placement. We had no complications associated with removal of the electrodes. In all cases, they were removed with the short-handled screwdriver or the spanner made by DIXI to avoid plunging.

Overall, there was no mortality, no neurologic deficit, and no infection observed. One patient developed headache 3 months after explantation of SEEG electrodes due to a venous thrombosis that resulted in edema in the left parietal lobe. However, an association between implantation and the venous thrombosis is unclear. The patient was treated with anticoagulants for 6 months and is now symptom-free.

A typical T2-weighted axial image is shown in Figure 1A. When seen along its plane, the electrode and each electrode contact are well-visualized. Figure 1B shows a sagittal T1-weighted image demonstrating the degree of metallic artifact. The actual diameter of the electrode is $0.8 \mathrm{~mm}$.
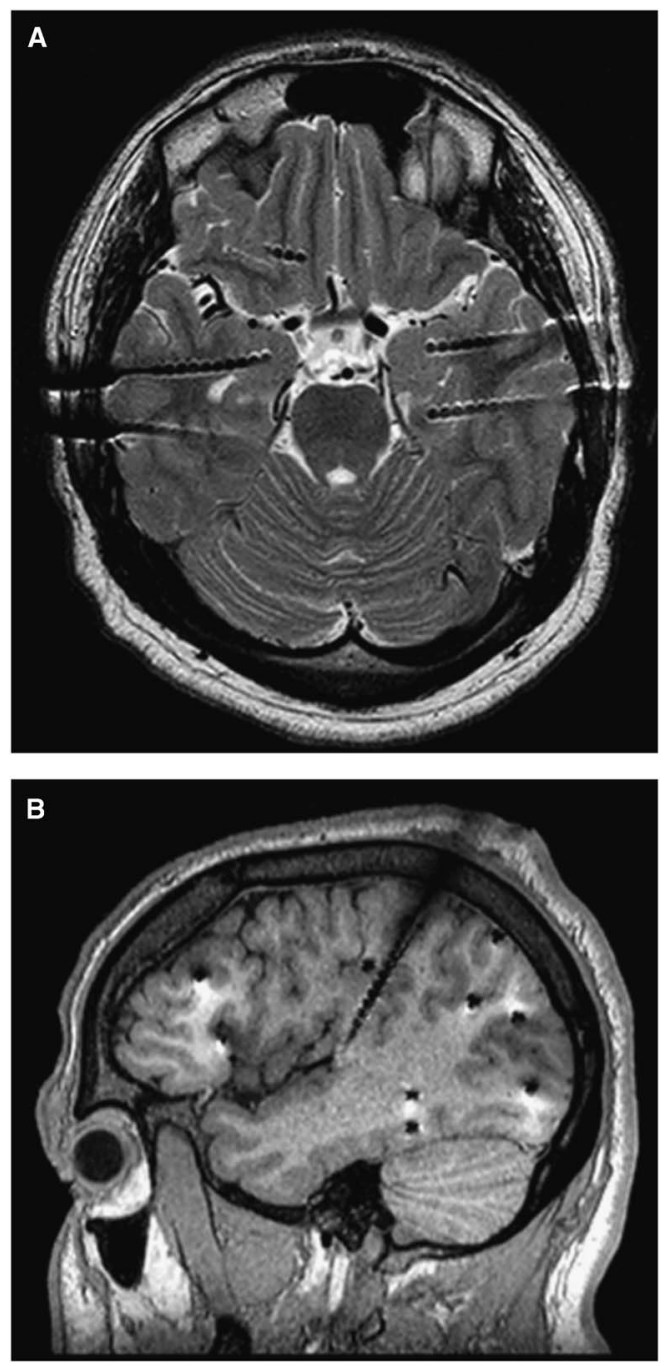

Figure 1: (A) An axial T2 section from an SEEG study for bitemporal epilepsy. When seen along its plane, the electrode and each electrode contact are well-visualized. (B) A sagittal T1 section from an SEEG study for frontal and posterior quadrant epilepsy. Electrodes were aimed at the orbitofrontal, temporal, and occipital areas from a lateral approach and the insula from a superior approach. A metallic artifact (appeared larger than the electrode diameter, $0.8 \mathrm{~mm}$ ) is appreciated.
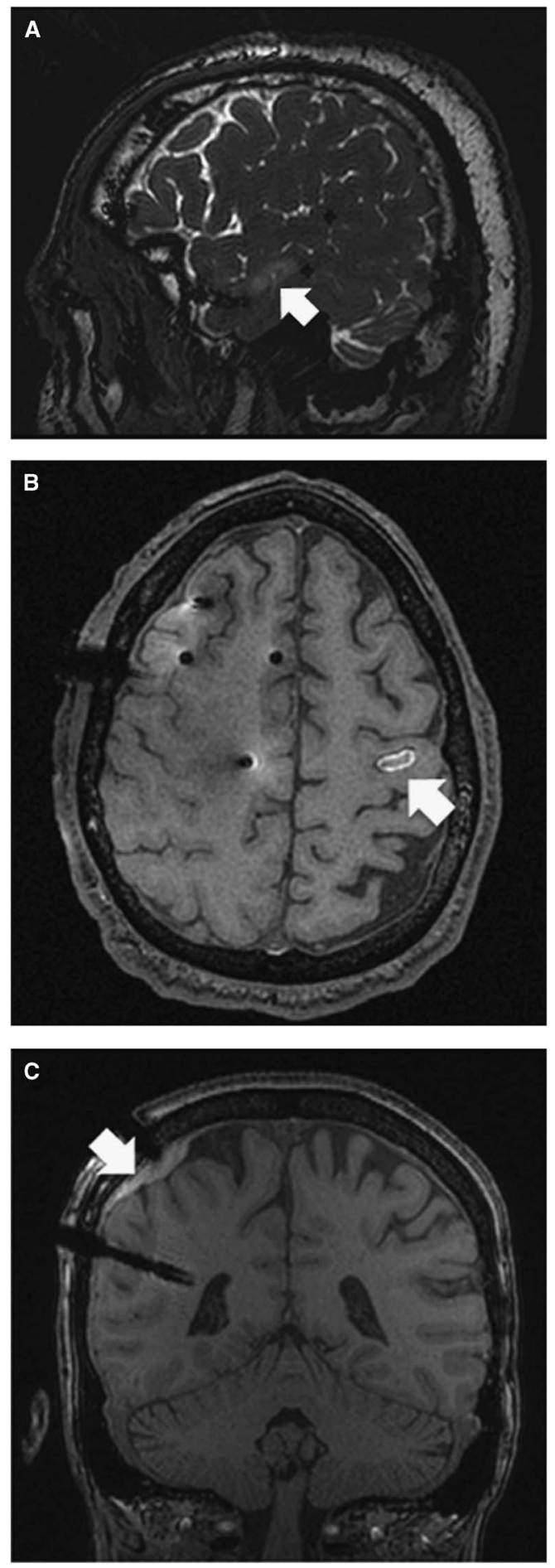

Figure 2: (A) Patient 12. T2 sagittal section showing a nonhemorrhagic contusion (white arrow) on the second temporal gyrus. The bone had been weakened by prior pin fixation where the anchoring screw penetrated the cortex. A small skin incision was required to retrieve the anchoring screw. (B) Patient 17. T1 axial section showing a hemorrhagic contusion most likely due to penetration of the cortex with the drill bit. This was not caused by insertion of the stylet or electrode since it was the intended site of an epidural contact. (C) Patient 6. T1 coronal section showing a subdural hematoma most likely due to unintended penetration of the dura and/or laceration of the cortical vessel. 

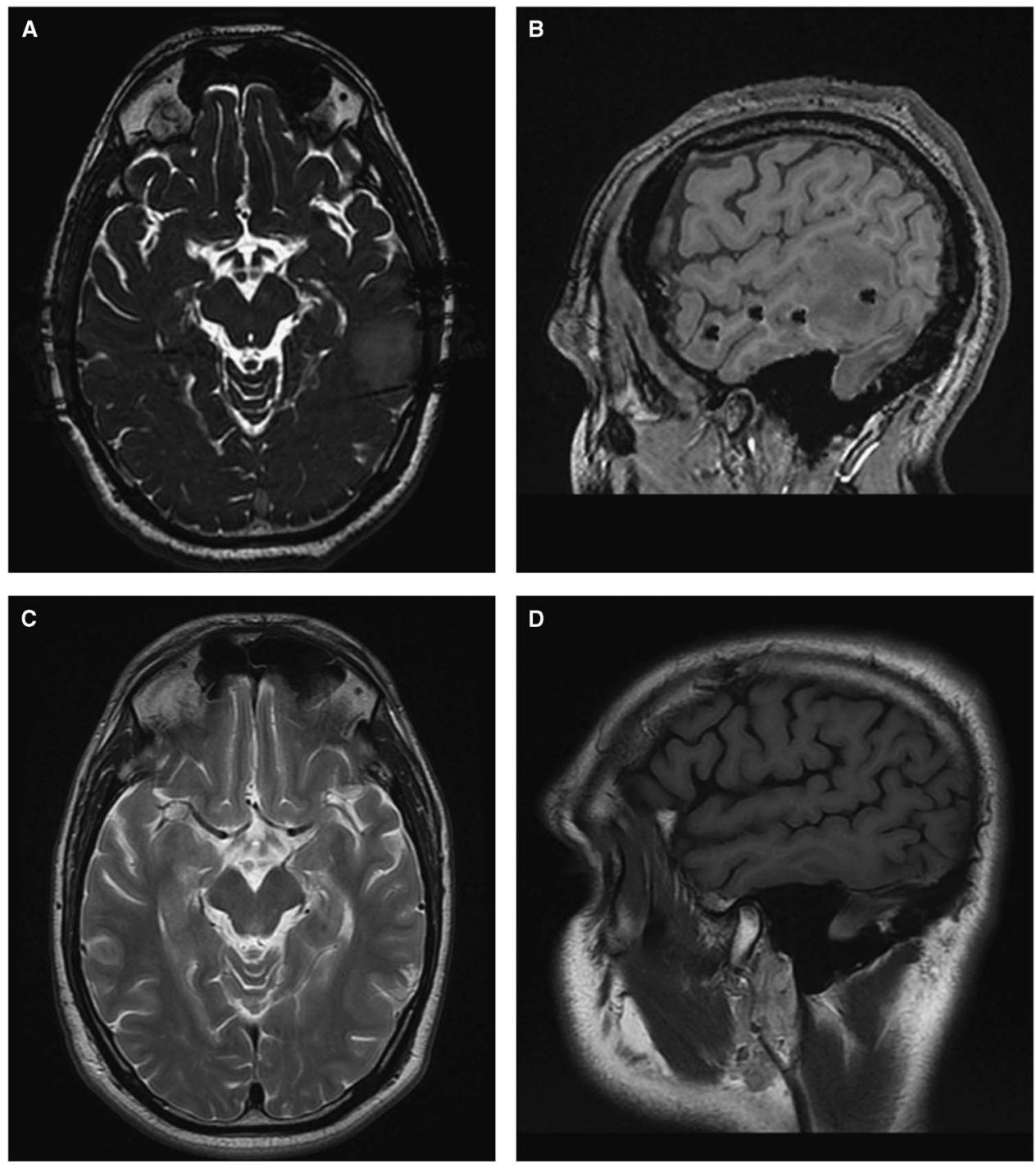

Figure 3: Patient 34. (A and $C) T 2$ axial section. ( $B$ and $D) T 1$ sagittal section. $A$ and $B$ show venous congestion in the left posterior temporal area most likely caused by compression or coagulation of a vein. $C$ and $D$ show these changes to be largely resolved at 3 months post-explantation.

A careful review of each patient's MRI with the electrodes in situ revealed four unexpected findings (three in the manual group and one in the robot-assisted group, $p=0.287$ ). Figure $2 \mathrm{~A}$ demonstrates an area of contusion without hemorrhage that resulted from a penetration of the anchoring screw through bone that had been weakened by previous pin fixation with the manual technique. Figure 2B shows a hemorrhagic contusion that likely occurred from an unintended perforation of the dura and cortex at the time of craniostomy with the manual technique. Figure $2 \mathrm{C}$ shows a subdural hematoma that likely occurred from an unintended perforation of the dura and/or laceration of a cortical vessel at the time of craniostomy with the manual technique. Figures $3 \mathrm{~A}$ and $3 \mathrm{~B}$ show venous congestion in the left posterior temporal area, most likely secondary to venous compression or coagulation with the robot-assisted technique. Figures $3 \mathrm{C}$ and 3D demonstrate its resolution at 3 months post-explantation.

Among the 49 patients in whom the SEEG findings were finalized, $31(63 \%)$ underwent therapeutic intervention (29 resections and 2 thermocoagulations). The MRI images with electrodes in situ were used for neuronavigation in all 29 who underwent resection. Seventeen patients were diagnosed with FCD on histopathology, while only 2 were positive for FCD on multiple preoperative MRI.

\section{Discussion}

The goal of the present study is to assess the safety and advantages of the current SEEG electrode implantation methodology in our center. Accuracy of frameless SEEG techniques has been extensively reported, ${ }^{6,9,10}$ and this is not our aim here.

Among the 53 patients who were implanted for an average duration of 2 weeks, with an average number of 10 electrodes, there was no mortality, no infection, and no new neurologic deficit. This rate of clinical complication is lower than that associated with other types of intracranial recording such as subdural strips or grids. ${ }^{11,12}$ Although the number of patients in this study is 
relatively small, the low rate of clinical complications with our technique is encouraging, as it is comparable to large series reported recently. $7,13,14$

Careful review of postimplantation MRI with electrodes in situ revealed four patients with asymptomatic radiological findings on MRI: three in the manual group and one in the robot-assisted group. The overall rate of asymptomatic radiologic complication was $7.54 \%$ per patient, or $0.72 \%$ per electrode. The overall rate of radiologic complication is slightly higher than that reported in a recent study. ${ }^{15}$ However, the modalities used for postimplantation evaluation of complication were different: CT in previous studies and MRI in this study. The difference in radiologic complication rate may be explained by the difference of sensitivity in detecting abnormalities between MRI and CT: MRI (in this study) is more sensitive than CT (in previous studies). Nevertheless, only one hemorrhagic complication was found in this series $(1.9 \%$ per patient, or $0.18 \%$ per electrode) and this rate is the same or even lower than the hemorrhagic complication based on CT findings in previous studies. ${ }^{4,7,9,15}$ While the use of robotics in neurosurgery remains in its infancy, ${ }^{16}$ the application to stereotactic procedures is advancing rapidly. ${ }^{17-19}$ The present study revealed that robotic assistance is safe to apply to stereotactic procedures.

A novel advantage provided by this technique is the ability to use the MRI with electrodes in situ for image-guided neuronavigation at the time of definitive resection. Under the guidance of MRI with electrodes in situ, resection yielded successful histopathological diagnosis of FCD in 15 patients who were MRInegative for FCD (88.2\% of all patients with FCD in this series). This suggests that neuronavigation using MRI images with electrodes in situ was useful to tailor definitive resection of the socalled "non-lesional" cases, which are often shown to be FCD on histopathology.

The safety of MR imaging of implanted depth electrodes has been a matter of debate. ${ }^{20}$ Despite evidence of studies demonstrating its safety under certain conditions, ${ }^{20-22}$ postimplantation MRI is still less popular to date because of safety concerns among some neuroradiologists and neurosurgeons. In agreement with previous studies, we did not find any complication after MR imaging in this series of patients. This further supports the safe use of MR imaging in localizing the implanted SEEG electrodes.

\section{Limitations OF THE STUdy}

While many centers are now moving towards 3-T MR imaging capabilities, the use of 1.5-T MR imaging in our presurgical workup is a limitation in terms of identification of focal cortical dysplasia, or any potential epileptogenic lesion. This may in part explain the patient cohort in whom our preimplantation MRI failed to identify focal cortical dysplasia.

Other limitations include the small number of patients and the retrospective nature of our study. Hence, the safety and complication rate figures reported here need to be taken with caution. The safety of our SEEG implantation methodology and the usefulness of MRI with SEEG in situ in clinical practice will be better demonstrated in a larger controlled prospective study.

\section{Conclusions}

We reported the technique, safety, and advantages of the current SEEG implantation methodology in our center. This is also the first reported series of MRI findings of patients with SEEG electrodes in situ. While the radiological changes were few and none were clinically significant, it nonetheless suggests that we should remain vigilant in refining the technique and restrict the number of electrodes to the minimum required to study a welldefined preoperative hypothesis regarding the seizure onset zone and propagation pathway. The use of MRI-compatible electrodes allows neuronavigation using the images with the electrodes in situ, which is useful to tailor the eventual definitive surgical resection.

\section{ACKNOWLEDGMENTS}

HMK is supported by a Mark Rayport and Shirley Ferguson Rayport fellowship in epilepsy surgery and was supported by the Preston Robb fellowship of the Montreal Neurological Institute, a research fellowship of the Uehara Memorial Foundation (Japan), and travel grants from the Osaka Medical Research Foundation for Intractable Diseases (Japan) and the Japan Epilepsy Research Foundation.

The authors thank Dr. J. Gotman and Dr. E. Kobayashi of the Montreal Neurological Institute and Hospital for their financial contributions (from their research grants) to partially offset the cost of the electrodes, Dr. M. Cortes of the Montreal Neurological Institute and Hospital for her professional advice and technical support in MRI sequences, and Dr. F. Dubeau for his professional support in retrieving detailed clinical data.

\section{Disclosures}

Dr. Khoo received support from a Mark Rayport \& Shirley Ferguson Rayport Fellowship in Epilepsy Surgery of the Montreal Neurological Institute and Hospital during the conduct of the study; and support from a Preston Robb fellowship of the Montreal Neurological Institute, the Uehara Memorial Foundation (Japan), the Osaka Medical Research Foundation for Intractable Diseases (Japan), and the Japan Epilepsy Research Foundation outside the submitted work.

Dr. Hall has nothing to disclose.

\section{STATEMENT OF AUTHORSHIP}

JAH was responsible for conception and design of the study. JAH and HMK were responsible for acquisition and analysis of data, drafting a significant portion of the manuscript, and the figures.

\section{REFERENCES}

1. Bancaud J, Talairach J, Bonis A, et al. La stéréo-électroencéphalographie dans l'épilepsie: informations neurophysiopathologiques apportées par l'investigation fonctionnelle stéreotaxique. Paris: Masson and Cie; 1965.

2. Bancaud J. Apport de l'exploration fonctionnelle par voie stéréotaxique à la chirurgie de l'épilepsie. Neurochirurgie. 1959; 5(1):55-112.

3. Espinosa J, Olivier A, Andermann F, Quesney F, Dubeau F, Savard G. Morbidity of chronic recording with intracranial depth electrodes in 170 patients. Stereotact Funct Neurosurg. 1994;63(1-4):63-5.

4. De Almeida AN, Olivier A, Quesney F, Dubeau F, Savard G, Andermann F. Efficacy of and morbidity associated with stereoelectroencephalography using computerized tomography-or magnetic resonance imaging-guided electrode implantation. J Neurosurg. 2006;104(4):483-7.

5. Tanriverdi T, Ajlan A, Poulin N, Olivier A. Morbidity in epilepsy surgery: an experience based on 2449 epilepsy surgery procedures from a single institution. J Neurosurg. 2009;110(6):1111-23. 
6. Chatillion CE, Mok K, Hall JA, Olivier A. Comparative study of manual versus robot-assisted frameless stereotaxy for intracranial electrode implantation. Paper presented at the Annual Meeting of the American Epilepsy Society; 2011.

7. Cardinale F, Cossu M, Castana L, et al. Stereoelectroencephalography: surgical methodology, safety, and stereotactic application accuracy in 500 procedures. Neurosurgery. 2013;72(3):353-66; discussion 366.

8. Olivier A, Boling WW, Tanriverdi T. Techniques in Epilepsy Surgery: The MNI Approach. New York: Cambridge University Press; 2012.

9. Gonzalez-Martinez J, Bulacio J, Thompson S, et al. Technique, results, and complications related to robot-assisted stereoelectroencephalography. Neurosurgery. 2016;78(2):169-80.

10. Vakharia VN, Sparks R, O'Keeffe AG, et al. Accuracy of intracranial electrode placement for stereoencephalography: a systematic review and meta-analysis. Epilepsia. 2017;58(6):921-2.

11. Burneo JG, Steven DA, McLachlan RS, Parrent AG. Morbidity associated with the use of intracranial electrodes for epilepsy surgery. Can J Neurol Sci. 2006;33(2):223-7.

12. Cardinale F, Cossu M. SEEG has the lowest rate of complications. J Neurosurg. 2015;122(2):475-7.

13. Bourdillon P, Ryvlin P, Isnard $\mathrm{J}$, et al. Stereotactic electroencephalography is a safe procedure, including for insular implantations. World Neurosurg. 2017;99:353-61.

14. Serletis D, Bulacio J, Bingaman W, Najm I, Gonzalez-Martinez J. The stereotactic approach for mapping epileptic networks: a prospective study of 200 patients. J Neurosurg. 2014;121(5):1239-46.
15. Gonzalez-Martinez J, Mullin J, Vadera S, et al. Stereotactic placement of depth electrodes in medically intractable epilepsy. J Neurosurg. 2014;120(3):639-44.

16. Camarillo DB, Krummel TM, Salisbury JK Jr. Robotic technology in surgery: past, present, and future. Am J Surg. 2004;188 (4A Suppl):2S-15S.

17. Abhinav K, Prakash S, Sandeman DR. Use of robot-guided stereotactic placement of intracerebral electrodes for investigation of focal epilepsy: initial experience in the $\mathrm{UK}$. Br J Neurosurg. 2013;27(5):704-5.

18. Spire WJ, Jobst BC, Thadani VM, Williamson PD, Darcey TM, Roberts DW. Robotic image-guided depth electrode implantation in the evaluation of medically intractable epilepsy. Neurosurg Focus. 2008;25(3):E19.

19. Gonzalez-Martinez J, Vadera S, Mullin J, et al. Robot-assisted stereotactic laser ablation in medically intractable epilepsy: operative technique. Neurosurgery. 2014;10 Suppl 2:167-72; discussion 172-3.

20. Davis LM, Spencer DD, Spencer SS, Bronen RA. MR imaging of implanted depth and subdural electrodes: is it safe? Epilepsy Res. 1999;35(2):95-8.

21. Carmichael DW, Thornton JS, Rodionov R, et al. Safety of localizing epilepsy monitoring intracranial electroencephalograph electrodes using MRI: radiofrequency-induced heating. J Magn Reson Imaging. 2008;28(5):1233-44.

22. Duckwiler GR, Levesque M, Wilson CL, Behnke E, Babb TL, Lufkin R. Imaging of MR-compatible intracerebral depth electrodes. AJNR Am J Neuroradiol. 1990;11(2):353-4. 